\title{
Blood Cancer Detection using Nano Amperometric Biosensor with Fluid Mechanics and Kinematic Variables
}

\section{Kalyan KB*}

Gitam University, Vizag, Andhra Pradesh, India

\begin{abstract}
In this paper I am going to present blood cancer detection using Fluid mechanics variables. Blood cancer is increasing in the world in an exponential manner. It is highly observed in India where smokers are too high in India. Even alcohol consumers are very high in INDIA, blood cancer patients are increasing in an exponential manner. I will be using biosensor for detecting the blood cancer directly through vitro protocol in this paper.
\end{abstract}

Keywords: Blood cancer; Biosensor; Fluid mechanic variables

\section{Introduction}

Biosensor is invented by Michael Clarke in 1962. It is also referred to as cell. It consists of a ligand and transducer. Ligand means biological element. The biological element used is Glucose oxidase. It is very costly and rare to buy in India. The biosensor is electro chemical type.

It is Amperometric biosensor whose output is in the form of current in order of milli amperes. Biosensors are increasing their importance day by day in the field of Biomedical Engineering. My PhD is on detection of blood cancer through Amperometric biosensor with Direct current cyclic Voltametry Technique. This is performed at CSIR LAB, CECRI and KARAIKUDDI. The software I used is electrocom software. The emerging Nano technology is also used in detection of cancer through Direct current cyclic voltammetry [1-4].

The Nano materials used are Graphene, Nano wires and Nano particles. Biosensor is composed with three electrodes namely Working Electrode, Counter electrode and Reference electrode. The working electrode is made of Glassy carbon, Reference electrode is made of Silver or Silver chloride and Counter electrode is made of platinum. The biosensor cell is kept to fridge for its location in low temperature which would work effectively in detection of pathogens.

\section{The Experimental Procedure}

a) First the biosensor cell is washed effectively without any foreign substance present on it.

b) The electrodes are given the following materials:

B1: Working electrode-Glassy carbon or AU.

B2: Reference electrode: $\mathrm{Ag}, \mathrm{Ag} \mathrm{Cl}$.

B3: Counter electrode: Platinum.

The above diagram shows the experimental setup of a cell connected to PC with electro com software (Figure 1).

c) The biosensor cell is tested with bare GC (glassy carbon) first bare refers to without any added chemical.

d) Next it is tested with Ferro ferri solution and connected to PC with Electrocom software.

e) There will be 2 domains in electro com software those are variable scan rate and fixed scan rate.

f) The biosensor should give output as 0.01 milli amperes and 0.01 volts peak to peak. g) Then it is ready for detection of pathogen.

h) Next after testing with BARE GC and FERRO FERRI, the enzyme is drop casted over the cell.

i) Next enzyme which I used in detection is Glucose oxidase given by the symbol GODx. All enzymes are proteins, but all proteins are NOT enzymes.

j) Proteins are very much essential for Human body. They can be obtained by eating Non vegetarian food like chicken, mutton, fish, prawns and crabs.

k) So proteins will be high in our human body like WBC, RBC.

l) Coming to current research enzymes which are all proteins are very much essential for human body for building a good and healthy body.

m) These proteins help in flow of blood in a smoother manner, so enzymes which are proteins are used for tracking the flow of blood in human body.

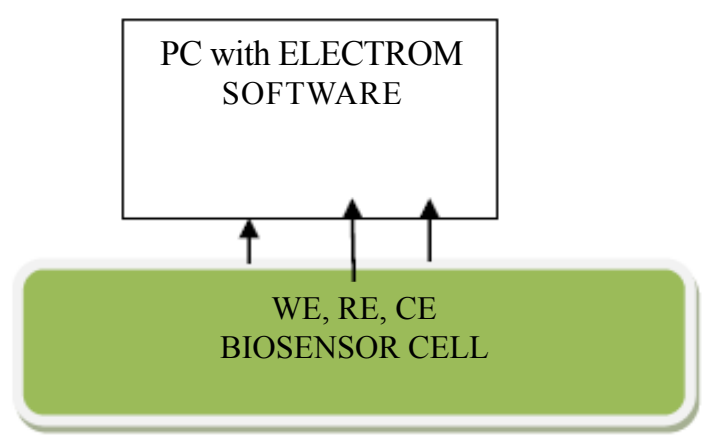

Figure 1: Block diagram of experimental SET up.

*Corresponding author: Kalyan Babu, Gitam University, Rushikonda-530045, Vizag, Andhra Pradesh, India, Tel: 8497917773; E-mail: kalyankillana@gmail.com

Received December 06, 2016; Accepted December 16, 2016; Published December 26, 2016

Citation: Kalyan KB (2016) Blood Cancer Detection using Nano Amperometric Biosensor with Fluid Mechanics and Kinematic Variables. J Biosens Bioelectron 7: 232. doi: $10.4172 / 2155-6210.1000232$

Copyright: (c) 2016 Kalyan KB. This is an open-access article distributed under the terms of the Creative Commons Attribution License, which permits unrestricted use, distribution, and reproduction in any medium, provided the original author and source are credited. 
n) Next, the cell is performed PANI (Electro chemical polymerization of analine)

o) The PANI is performed by mixing HCL and ANILINE in equal proportions.

p) Next the GODX is drop casted on the working electrode which is mobilization of enzyme on cell which increases the current output which is good healthy body cancer.

q) Next the cell is poured with analyte (blood -on whom the analysis is carried out).

r) The cancerous blood reacts with GODx enzyme and reveals very low current order of Micro and Nano amperes.

s) Healthy blood on reaction with GODx electrode reveals high output current in order of milli amperes.

t) The cancer cell is very flexible, loses contact with human body, very less count of WBC, RBC, Proteins and glucose.

u) The cross verification is done by clicking Load cell in Electrocom software.

v) By clicking load cell we can visualize Non-Cancerous blood and Cancerous blood.

w) This characteristic graph with cancer will be low in terms of current.

x) The characteristic graph for without cancer will be very high graph output in terms of current.

y) The above steps are used in my research in detection of any cancer.

z) The cancerous blood is poured in to the wash basin carefully and is cleaned very accurately with distilled water.

\section{Core Theory of the Paper}

In this paper, I am using BERNOULII equations in detection of blood cancer [5-8].

The Nano technology: The usage of Nanotechnology is increasing rapidly day by day in the field of Biosensors.

The Nano technology materials are Graphene. This is best suited for biological applications. The Graphene is decomposed from graphite material which is solid like material and hardest material in the universe. The research on Nanotechnology is emerged with Bucky ball configuration which obtained Nobel Prize for the configuration. In addition to grapheme rods CNTs are also used in biosensor construction. The CNT stands for Carbon Nano tubes which are numerous in the field of hardest materials.

$\mathrm{P}+1 / 2 \mathrm{DV}$ exp $2+\mathrm{Dgh}=$ constant

$\mathrm{P}=$ Pressure

$\mathrm{D}=$ Density

$\mathrm{h}=$ Elevation Height

$\mathrm{G}=$ acceleration due to gravity.

The above equations ratify the Bernoulli Equations.

For normal healthy blood, Blood Pressure will be 120/80.

So, $\mathrm{P}$ in the above equation should be constant.
P will be high for cancerous blood cells resulting slight heart attack.

The simulation is carried out with $\mathrm{P}$ (Pressure) as very high (variable) for cancerous blood cells and constant for non-cancerous blood cells.

In addition to pressure variable the next parameter to be considered is $\mathrm{D}$ (Density).

Density is also found to be constant for healthy cells and very high for cancerous cells.

The next parameter to be considered is h, elevation height.

It is very vigorous for cancerous cells and normal for healthy blood cells.

$\mathrm{G}$ is acceleration due to gravity. Its value is $9.8 \mathrm{~m} / \mathrm{sec} 2$.

\section{Additional equations}

1. $\mathrm{V}=\mathrm{u}+\mathrm{at}$ (from the basics of dynamics or kinematics)

$\mathrm{V}=$ final velocity

$\mathrm{u}=$ initial velocity

$\mathrm{a}=$ acceleration

$\mathrm{t}=$ time.

For human body the equation is reformed as $\mathrm{V}=$ at. Assuming the initial velocity is zero for blood flow.

If the velocity is uniform, the value of a will be zero.

Then $\mathrm{V}=\mathrm{U}$.

2. $V \exp (2)-U \exp (2)=2^{*} a^{*} s$.

s Stands for displacement.

For human body the value of $\mathrm{S}$ is found to be constant.

Because the human heart which is pumping the blood move with uniform velocity and reaches the brain in constant displacement.

$\mathrm{V}=$ Final velocity.

$\mathrm{U}=$ Initial velocity.

3. h Elevation height: This is a high variable constant.

The value of $h$ is very high for cancerous cells and constant for healthy cells

Because the cancer cells become heavy mass initially and become very less mass after stipulated amount of period [7].

\section{Further equation developed}

$\partial \mathrm{P} / \partial \mathrm{T}+1 / 2 \partial \mathrm{D} / \partial \mathrm{T} . \mathrm{V} \exp 2+\partial \mathrm{D} / \partial \mathrm{T}^{\star} \mathrm{g}^{\star} \mathrm{h}=$ constant.

The above equation reveals the change in variables like pressure, density with respect to time.

\section{Blood cancer symptoms}
a) High fever
b) Head ache
c) Sudden weight loss
d) Fatigue, weak ness
e) Pains in joints 
Citation: Kalyan KB (2016) Blood Cancer Detection using Nano Amperometric Biosensor with Fluid Mechanics and Kinematic Variables. J Biosens Bioelectron 7: 232. doi: 10.4172/2155-6210.1000232

Page 3 of 3

\begin{tabular}{|c|c|c|}
\hline Cancer & Non cancer & \\
\hline P -HIGH & CONSTANT & P- PRESSURE \\
\hline D-HIGH & CONSTANT & D-DENSITY \\
\hline H-High & CONSTANT & H-ELEVATION HEIGHT \\
\hline I-LOW & HIGH & I- CURRENT \\
\hline
\end{tabular}

Table 1: Cancer variables in terms of Pressure, Density and Elevation height.

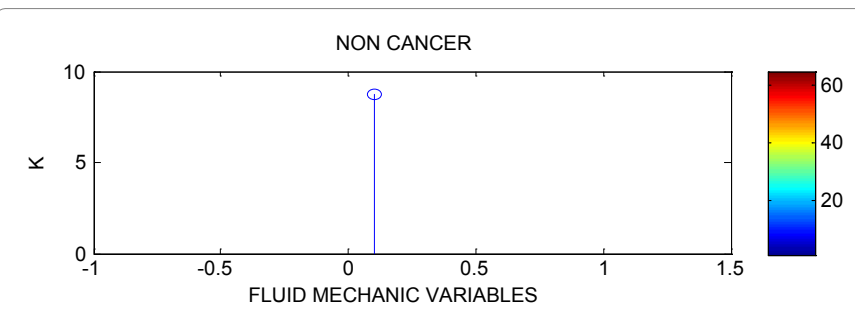

Figure 2: Non cancerous fluid mechanic variables.

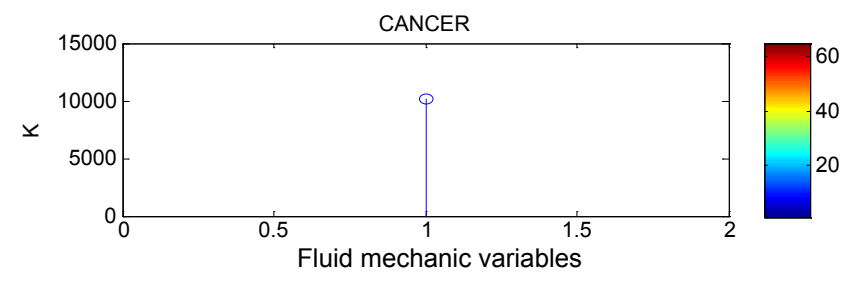

Figure 3: Cancerous fluid mechanic variables.

f) Excess sweating

g) Zero count of red blood corpuscles.

h) Rough skin

i) Smooth skin turning into rough skin.

\section{Numerical simulation}

a) For cancerous cells, $\mathrm{P}$-pressure will be high. For Non-cancerous cells, $\mathrm{P}$ will be constant.

b) D-Density is found to be high for cancerous cells and constant for Non-cancerous cells. c) Elevation height-h will be very high for cancerous cells and constant for non-cancerous cells (Table 1).

The above table reveals cancer variables are very high in terms of Pressure, Density and Elevation height.

It is reverse in terms of current [6].

With the above equations, a program is written in MATLAB 13 software and results are plotted as shown below.

\section{Results}

The above results show the Cancer and Non-cancerous cells Variation of fluid mechanic variables (Figures 2 and 3).

\section{Conclusion}

The above 2 graphs show the results of Non cancer and Cancer cells respectively, for the variation of $\mathrm{K}$ with Fluid mechanic variables. Where $\mathrm{K}=\mathrm{P}+1 / 2 \mathrm{DV}$ exp2+Dgh.

So in this research article, I presented the detection of Blood cancer using fluid mechanics variables.

As blood is a moving liquid, I considered Fluid mechanics and Kinematics variables in detection of Blood cancer.

\section{References}

1. Eom K (2011) Simulations in Nano Biotechnology. CRC press pp: 1-6.

2. Lim TC (2010) Nano sensors: Theory and applications in Industry, Healthcare and defense. CRC press PP: 100-125.

3. Baronas R, Ivanauskas F, Kulys J (2010) Mathematical modelling of Biosensors: An Introduction for Chemists and Mathematicians. Springer Series on Chemical Sensors and Biosensors.

4. https://en.wikipedia.org/wiki/Fluid_mechanics

5. Bhansal RK (2014) Fluid mechanics and Hydraulic machines. S.I units pp: 1-100.

6. Supriyo Datta (2013) Fundamentals of Nanoelectronics: Basic Concepts.

7. http://study.com/academy/topic/kinematics-in-physics.html.

8. Preddy RV, Patel V (2012) Biosensors and cancer. CRC press, UK 